Journal of Applied Fluid Mechanics, Vol. 15, No. 1, pp. 245-253, 2022.

Available online at www.jafmonline.net, ISSN 1735-3572, EISSN 1735-3645.

https://doi.org/10.47176/jafm.15.01.32940

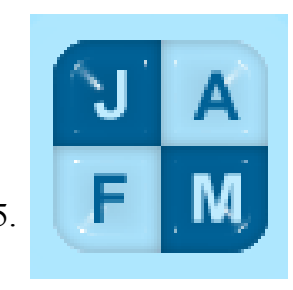

\title{
A Choking Cavitation Method and Equipment for Degrading Pollutants in Wastewater
}

\author{
Z. N. Wang ${ }^{1 \dagger}$, R. Z. Gong ${ }^{2}$, H. Long ${ }^{2}$, H. Liu ${ }^{1}$, G. Cheng ${ }^{3}$ and F. H. Zhang ${ }^{3}$ \\ ${ }^{1}$ School of mechanical engineering, Hunan University of Science and Technology, Xiangtan, 411201 \\ ${ }^{2}$ School of Business, Hunan University of Science and Technology, Xiangtan 411201 \\ ${ }^{3}$ School of Mechanical Engineering, Hunan University of Technology, Zhuzhou 412007
}

†Corresponding Author Email: wzn101315@163.com

(Received April 29, 2021; accepted August 9, 2021)

\begin{abstract}
A cavitator, with a structure of an annular conical aperture, a throat and a collapse cavity, was proposed to form a choking cavitation flow for pollutants degradation in wastewater treatment. Experiment was conducted in this new cavitator to investigate its flow characteristics and pollutant degradation ratio by employing Mythylene blue (MB) as a pollutant in pure water. It was found that choking cavitation flow appears in the throat by controlling the pump pressure and liquid flow rate in a rule. The pollutant degradation ratio in choking cavitation flow is much larger than that in normal cavitation flow, because plenty of cavitation vapours are born, grow up, and finally collapse in this cavitator in the choking cavitation condition. Gemetrical parameters also affect pollutant degradation ratio, and the optimal gemetrical parameters for this proposed cavitator are suggested.
\end{abstract}

Keywords: Cavitation; Choking flow; Degradation; Throat; Pollutants.

NOMENCLATURE

$\begin{array}{ll}A_{t} & \text { throat cross-sectional area } \\ A_{t l} & \text { liquid effective flow area } \\ A_{b} & \text { spectrophotometer absorbance } \\ C & \text { mass concentration of MB } \\ C_{0} & \text { initial MB concentrations } \\ c_{t} & \text { contraction coefficient } \\ D e & \text { degradation rate } \\ D_{t} & \text { throat diameter } \\ D_{c} & \text { collapse cavity diameter } \\ J_{t} & \text { superficial liquid velocity in throat } \\ k & \text { degradation rate constant } \\ L_{t} & \text { throat length }\end{array}$

\section{INTRODUCTION}

In recent years, our wastewater problem becomes more and more serious. The common physical, chemical and biological treatment methods can no longer satisfy the safety, health and environmental goals when removing the contaminants from wastewater. Thus, it is becoming increasingly important to develop new methods for the rapid and efficient removal of a wide range of contaminants

$\begin{array}{ll}L_{c} & \text { collapse cavity length } \\ P_{a} & \text { ambient pressure } \\ P_{c} & \text { pressure in collapse cavity } \\ P_{o} & \text { pump pressure } \\ P_{s} & \text { the pressure behind of shock section } \\ P_{t} & \text { liquid pressure in throat } \\ P v & \text { vapour pressure } \\ Q & \text { liquid flow rate } \\ v_{t} & \text { liquid velocity in throat } \\ \rho_{l} & \text { liquid density } \\ \alpha & \text { annular conical slot angle } \\ \varepsilon_{s} & \text { the void fraction at shock section }\end{array}$

from polluted water (Pawar et al. 2017, Sarc et al. 2017).

Hydrodynamic cavitation is recognized as one of the most promising methods for wastewater treatment, because it degrades pollutants under a normal temperatures and low pressures without any chemical additives. Cavitation produces a strong chemical action and a mechanical break-up for the destruction of complex organic chemicals, biorefractory materials, etc in wastewater. Violent 
collapse of the cavities results in the formation of reactive hydrogen atoms and hydroxyl radicals which degrades most of organic pollutants in wastewater into harmless substances. Moreover, a strong hydraulic shear stress caused by cavities collapse can kill microorganisms by destructing their cell walls (Badmus et al. 2018, Rajoriya et al. 2017). Recently, cavitation begins to be widely used in the food industry, wastewater treatment. For example, Lohani et al. (2016) employed a hydrodynamic cavitation to improve antioxidant activity in sorghum flour and apple pomace. He found that antioxidant activity increased by $37 \%$ and $97 \%$ in sorghum flour and apple pomace, respectively. Langone et al. (2015) invented a hydrodynamic cavitation system for the treatment of wastewater, and he found this device has a strong effect on sludge solubilisation, on biodegradability improvement and on microbial activity. Until now, many researchers have designed a lot of hydrodynamic cavitators, such as: jet cavitator, orifice cavitator, swirling jet-induced cavitator, etc.

For jet cavitation, it is formed in some special cavitation nozzle under a high liquid pressure. Li et al. (2016, 2017) designed organ-pipe nozzles and investigated their cavitation erosion intensity under pump pressures of $10,15,20$, and $25 \mathrm{MPa}$. He found that the feeding pipe diameter greatly influenced the hydro-acoustic waves and the self-resonance of organ-pipe nozzles. Liu et al. (2017) designed a Helmholtz nozzle and analyzed the interaction between the cavitation and the vortex formation. He found that cavitation clouds in the chamber dominate the oscillating frequency. Both of them showed that these nozzles could produce some cavitation jet for cavitation fatigue and impact rupture, which could be widely used in water-jet crushing and cleaning fields. But jet cavitation usually occurs under a high pressure as large as several to tens of $\mathrm{MPa}$, which is not economic for wastewater treatment due to a large energy consumption.

The second type is orifice cavitation. Cavitation vapours are formed in the downstream of orifice plates due to a pressure drop in the orifice plates. Sivakumar and Pandit (2002) treated a dye solution using multiple orifice plates, and found that there was substantial enhancement in the extent of degradation of this dye solution using multiple orifice plates. Vichare et al. (2000) studied the hydrodynamic cavitation of the orifice plates and he suggested the plate with a small size opening could increase the area of the shear layer. This kind of orifice cavitator can produce cavitation vapours under a small pressure condition (below to $1 \mathrm{MPa}$ ), but has no ability for totally rupture these cavitation vapours in the downstream due to a small pressure gradient in the orifice plates.

In swirling jet-induced cavitator, liquid is injected from the tangential injection port, and passes through the swirling cavitation chamber circularly. It produces cavitation vapours in the formed low central pressure region. Wang et al. (2008) conducted an investigation of the chemical effect of swirling jet-induced cavitation on degrading a cationic dye rhodamine $\mathrm{B}$ in aqueous solution, and he found that the swirling jet-induced cavitation is more energy efficient as compared to sonochemical cavitation. Mancuso et al. (2016) further found that sludge solubilization and aerobic biodegradability can be efficiently enhanced by using swirling jetinduced cavitation. Compared with orifice cavitation, swirling jet-induced cavitators could also work under a low inlet pressure but has a problem in collapsing cavitation vapours.

The above cavitators have been proved to have a capacity for wastewater treatment. But their degrading efficiency is still not high enough. As we know, a high-efficient cavitation degradation not only needs a high concentration of generated cavitation vapours, but also needs an effective means for rupturing these vapours. However, it is usually difficult to achieve the above two goals, simultaneously, because the generation of vapour needs a low pressure in the upstream while the collapse needs a high pressure in the downstream. For example, a high ambient pressure in the downstream is benefit for vapour collapse, but suppresses the vapour formation and its growth up.

Choking flow is a good way to solve the above contradiction. Once the vapour-liquid mixture reaches to its local sound velocity in discharge line, a choking line would be established as reported by Nilpueng and Wongwises (2011), which just like a valve dividing the flow into two isolated system: the upstream one with a low pressure for vapour generation and growth up, and the downstream one with a high pressure for vapour collapse. For this choking flow, adjusting the pressure in the downstream would not change the pressure distribution in its upstream, as said by Akmandor and Nagashima (2015), Trapp and Ransom (1982). This was good news for highly efficient cavitation.

Thus, we proposed a choking cavitation method for degrading pollutants in wastewater, and designed a choking cavitator according to the gas-liquid two phase choking flow theory. For this cavitator, a highspeed camera was employed to visually investigate the cavitation vapours. And Mythylene blue (MB) was chosen as a pollutant in pure water for degradation experiment to test the degradation efficiency.

\section{THE CHOKING THEORY AND CAVITATOR STRUCTURE}

The cavitator, designed in this experiment, is shown in Fig.1. An annular conical structure with a small aperture is used to form a high-speed jet. This jet is injected into the downstream throat with an inclined flow angle, creating a large area of shear layer and aggressive cavitation events, as shown in Fig.1. Compared with other cavitators, this annular conical structure greatly enhances the surface area of shear layer and creates more microscopic cavitation vapours.

Vapours are continuously generated in the shear layer, grow up and flow along the throat. This results in a sharp decrease of the local speed of sound due to an increase of void fraction along the throat. It was 
reported that the sound speed in vapour-liquid mixture can fall to values below $25 \mathrm{~m} / \mathrm{s}$, almost 20 times below that of saturated vapour and 60 times below that of pure water. If the mixture flow reaches to its sound speed in somewhere of the throat, the local Mach number is approximate to 1 , a choking flow and shock phenomenon will be formed.
A choking flow formed at Mach number equaling to 1 is very important, because the shock section divides the flow into two isolated parts: an upstream one with a low pressure which is benefit for vapour generation and growth up, and a downstream one with a high pressure which is good for vapour collapse.

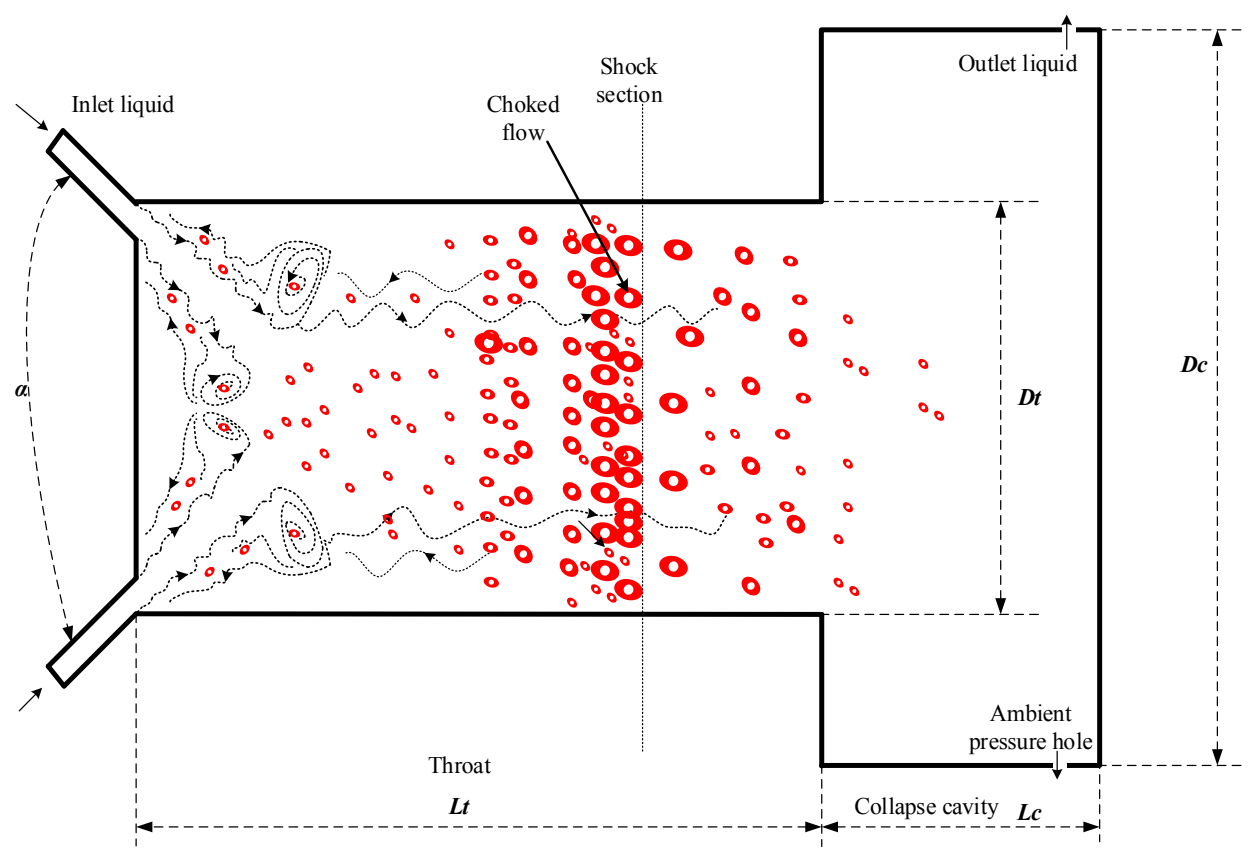

Fig. 1. The principle of choking cavitator.

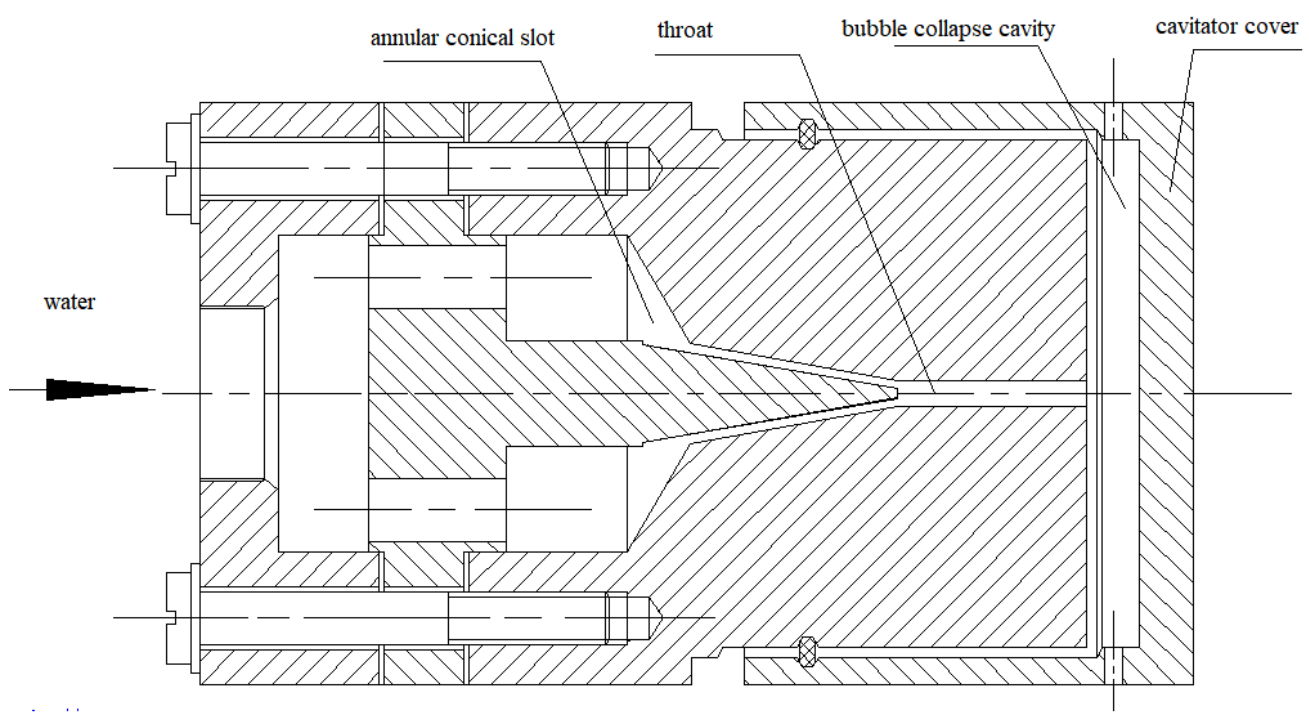

Fig. 2. Structure of choking cavitator.

A free streamline flow model could be applied to predict the choking flow condition. The pressure in the pump export is equal to the sum of static and dynamic pressure in the throat if neglecting its 
pressure loss, as follows:

$$
P_{o}=P_{t}+\frac{1}{2} \rho_{l} v_{t}^{2}
$$

where, $P_{o}$ is the pump pressure, $P_{t}$ the liquid pressure in throat, $\rho_{1}$ the liquid density, $v_{t}$ the liquid velocity in throat.

Liquid is injected from annular conical aperture into throat and produces a contraction effect, resulting in a reduction of effective flow area in throat. According to mass continuity of liquid in throat, its mass flow rate could be written as follows:

$$
\rho_{l} J_{t} A_{t}=\rho_{l} v_{t} A_{t l}=\rho_{l} v_{t} c_{t} A_{t}
$$

where, $A_{t}$ is the throat cross-sectional area, $A_{t l}$ the liquid effective flow area, $J_{t}$ the superficial liquid velocity in throat, $c_{t}$ the contraction coefficient, which was about $0.612-0.757$, measured by Rouse and Abul-fetouh (1950).

Substituting Eq. (2) into Eq. (1), and rearrangement, yield,

$$
P_{o}=P_{t}+\frac{1}{2} \rho_{l}\left(\frac{J_{t}}{c_{t}}\right)^{2}
$$

If the Mach number in throat reaches to 1 , a choking criterion is satisfied with a phenomenon that the pressure along the throat reaches its minimum value and its liquid velocity reach its maximum. Griebe et al. (1970) investigated the critical choking condition and claimed that this minimum pressure approximately equals to the vapor pressure because liquid can sustain and is not appreciably influenced by the presence of dissolved gases in the liquid. Thus, for the choking condition, Eq. (3) could be rewritten as,

$$
P_{o}=P_{v}+\frac{1}{2} \rho_{l}\left(\frac{J_{t}}{c_{t}}\right)^{2}
$$

where, $P_{v}$ the vapour pressure.

Once this choking flow is formed, its liquid velocity would reach its maximum and pressure reaches its minimum. This is more beneficial for the birth and grows up of cavitation vapours. Moreover, a shock section will be established at fully developed choking flow. This shock section divides the flow into two parts: a low pressure region ahead of the shock and a high pressure region behind the shock. As it is mentioned above, a vapor pressure sustains in the choking flow ahead of the shock. But a step pressure rise occurs at the shock section. Griebe et al. (1970) proposed a pressure behind the shock region according to the conservation of mass and momentum,

$$
P_{s}=P_{v}+\frac{1}{2} \rho_{l} J_{t}^{2}\left(\frac{2 \varepsilon_{s}}{1-\varepsilon_{s}}\right)
$$

where, $P_{s}$ the pressure behind of shock section, $\varepsilon_{\mathrm{s}}$ the void fraction at shock section.

At the end of throat, a collapse cavity with an expansion structure is designed by referring to the structure of Griebe et al. (1970). Griebe et al. (1970) used this expansion structure to further increase pressure for vapour collapse,

$$
P_{c}=P_{s}+\frac{1}{2} \rho_{l} J_{t}^{2}-\frac{1}{2}\left(1-\frac{D_{t}^{2}}{D_{c}^{2}}\right)^{2} \rho_{l} J_{t}^{2}
$$

where, $P_{c}$ the pressure in collapse cavity.

It could be found that the pressure in collapse cavity is larger than that in region behind the shock section, which is very benefit for vapour collapse. In this device, the key is to form a shock section, which divided the flow into a low pressure region and a large pressure region. In the low pressure region, a choking flow with a maximal liquid velocity and minimal pressure provide an optimal condition for the birth and grow up of cavitation vapours. In the high pressure region and the following collapse cavity, the developed vapours are easy to collapse and produce a strong decontamination effect.

\section{EXPERIMENTS}

\subsection{Experimental apparatus}

The circulatory system was a closed loop system, as shown in Fig. 3. It consisted of a pump (type: 1W2.5-12, maximal flow rate $2.5 \mathrm{~m}^{3} / \mathrm{h}$ ), a cavitator and a water tank. Water was pumped from the water tank into the cavitator (as shown in Fig. 2), and was finally discharged back into the tank through the holes in the cavitator cover. The geometry of the cavitator used in this experiment was shown in Tab.1. In the experiment, the cavitator was deeply submerged in the tank, below the liquid level in order to avoid any induction of air into the system. Also, a cooling jacket was mounted in the tank to keep the water in a room temperature. To obtain the inlet flow rate of this cavitator, a turbine flow-meter (type: LWGY $\backslash D$ 1) with a range of $0.4-8.0 \mathrm{~m}^{3} / \mathrm{h}$ was employed. To obtained the inlet and outlet pressure of this cavitator, two pressure gauges (type: Y-100-0-1) with a range of 0-2 $\mathrm{MPa}$ were also employed in this system.

Table 1 Geometry of choking cavitator

\begin{tabular}{|c|c|c|c|c|c|}
\hline Symbol & $\alpha$ & $\mathrm{L}_{\mathrm{t}}$ & $\mathrm{D}_{\mathrm{t}}$ & $\mathrm{L}_{\mathrm{c}}$ & $\mathrm{D}_{\mathrm{c}}$ \\
\hline Value & $15^{\circ}$ & $\begin{array}{c}40 \\
\mathrm{~mm}\end{array}$ & $\begin{array}{c}10 \\
\mathrm{~mm}\end{array}$ & $\begin{array}{c}40 \\
\mathrm{~mm}\end{array}$ & $\begin{array}{c}100 \\
\mathrm{~mm}\end{array}$ \\
\hline
\end{tabular}

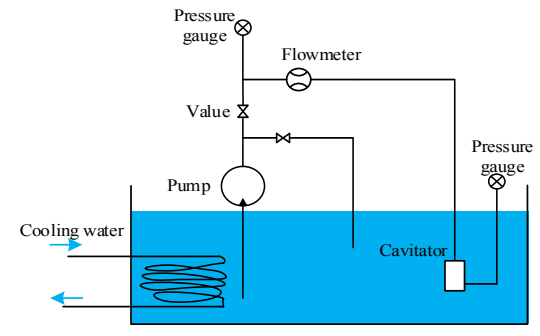

Fig. 3. Experimental flow system. 


\subsection{Visualization study}

To visually study the cavitation vapours in cavitator, pure water was firstly used in this experiment and a high-speed camera (type: PhantomM310-12G) with a shooting frequency $500 \mathrm{~Hz}$ was employed to capture the images of cavitation vapours, as shown in Fig. 4. Considering the small size of cavitation vapours, a lens with zoom function was used, which could magnify images 3 times larger.

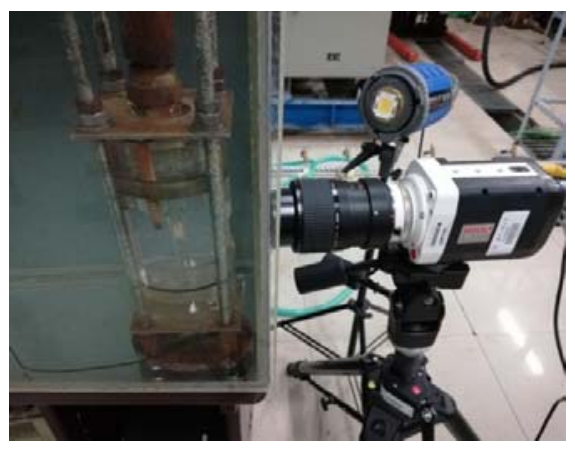

Fig. 4. Visually measurement by camera.

\subsection{Degrading pollutants in liquids}

The collapse of cavitation vapour generated localized "hot spots" with transient temperature of about $5000 \mathrm{~K}$ and pressures as high as $1000 \mathrm{~atm}$, as said by Mcnamar et al. (1999) and Didenko et al. (1999). Under this condition, Water could be dissociated into hydroxyl radical and hydrogen radicals resulting in a strong capacity of degrading pollutants in liquid. In this experiment, Mythylene blue (MB) was chosen as a pollutant in water. A series of MB solutions with different concentrations ( $4 \mathrm{mg} / 1,6 \mathrm{mg} / \mathrm{l}, 8 \mathrm{mg} / \mathrm{l}, 10 \mathrm{mg} / \mathrm{l}, 12 \mathrm{mg} / \mathrm{l})$ with initial volumes $(30 \mathrm{~L})$ were employed to test the corresponding capacities of degradation efficiency. A spectrophotometer (type: 723N) made by JINHUA instrument company, China was employed to measure the $\mathrm{MB}$ concentration. For a concentration range of $0-15 \mathrm{mg} / \mathrm{l}$, the absorption coefficient is directly proportional to the MB concentration at a working wave length $640 \mathrm{~nm}$ :

$$
A=0.2235 C-0.0223
$$

where, $\mathrm{C}$ was the mass concentration of $\mathrm{MB}, \mathrm{A}$ the absorbance.

\section{RESULTS AND DISCUSSIONS}

\subsection{Choking characteristics}

The liquid flow rate was recorded under different ambient pressures and a constant inlet pressure 1.1 $\mathrm{MPa}$, as shown in Fig. 5. It could be found that the measured liquid flow rate could be divided into two different flow regions as depicted by the line, in Fig. 5. In the first region $\left(0.7 \mathrm{MPa}<\mathrm{P}_{\mathrm{a}}<1 \mathrm{MPa}\right)$, liquid flow rate decreased with the increase of ambient pressure. While in the second region $(0.4$ $\mathrm{MPa}<\mathrm{Pa}_{\mathrm{a}}<0.7 \mathrm{MPa}$ ), liquid flow rate almost kept constant with the decrease of ambient pressure. That's to say, for a given upstream pressure, a maximum flow rate existed and a further reduction in the downstream pressure did not result in an increase of liquid flow rate. This flow mechanism was a choking cavitation flow.

For choking cavitation flow, its maximum liquid flow rate was related to the pump pressure. Thus, a series of liquid flow rates were measured under different choking flow conditions at different pump pressures, as shown in Fig. 6. It was found that experimental data was in agreement with the predicted model (in Eq. (4)). This was meaningful for us to keep the flow in choking cavitation state because only the pump pressure and flow rate should be controlled in a rule as shown in Fig. 7.

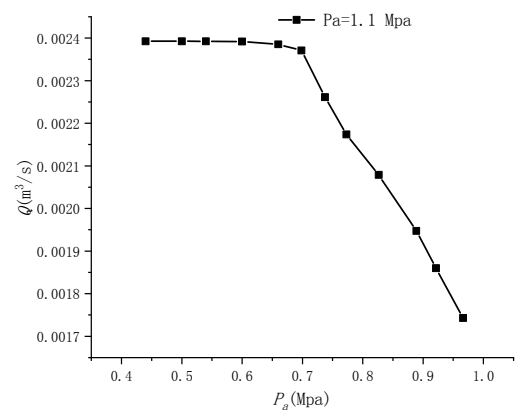

Fig. 5. Liquid flow rate versus ambient pressure under an inlet pressure 1.1 MPa.

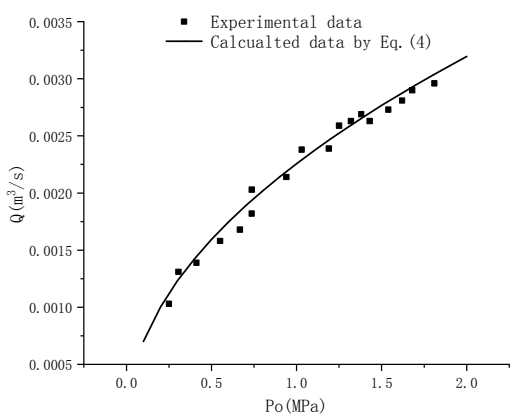

Fig. 6. Liquid flow rate versus pump pressure under choking flow condition.

To investigate the development process of choking flow in this experimental cavitator, cavitation images at different pump pressures and different flow rates were captured. Figure 7 showed the flow regimes in throat under different flow rates at a constant inlet pressure 1.1 $\mathrm{MPa}$. For a small liquid flow rate $\left(\mathrm{Q}<0.0007 \mathrm{~m}^{3} / \mathrm{s}\right)$, a single-phase liquid flow appeared in throat because the jet velocity in annular aperture was not large enough to form a cavitation event in the entrance of throat. When the liquid flow rate exceeded $0.0007 \mathrm{~m}^{3} / \mathrm{s}$, obvious cavitation vapours could be seen in the throat as shown in Fig. 7(a). Still increasing the liquid flow rate, a cavitation 
cloud was seen in the shear layer as shown in Fig. 7(b). When the liquid flow rate increased to about $0.0024 \mathrm{~m}^{3} / \mathrm{s}$, a vapour foam flow was found in throat, as shown in Fig. 7(c). It should be noted that the flow regime in Fig. 7(c) was a choking flow, because its flow rate already reached its maximum.

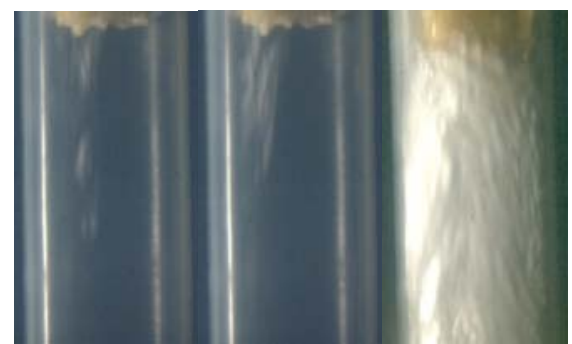

(a) $\mathrm{Q}=0.0007 \mathrm{~m}^{3} / \mathrm{s} \quad(\mathrm{b}) \mathrm{Q}=0.0018 \mathrm{~m}^{3} / \mathrm{s} \quad(\mathrm{c}) \mathrm{Q}=0.0024$ $\mathrm{m}^{3} / \mathrm{s}$

Fig. 7. Cavitation in the throat at different liquid flow rates and a constant inlet pressure 1.1 MPa.

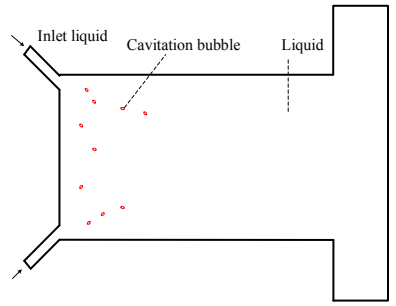

(a) Cavitation vapour flow

(b)

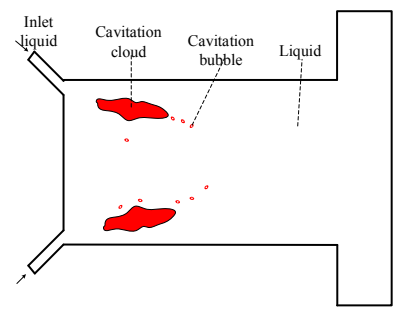

(c) vapour cloud flow

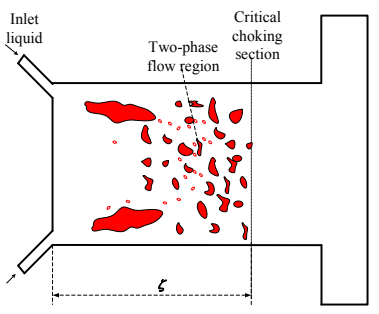

(c) Choking cavitation flow

Fig. 8. Flow regimes in cavitator.

Three sketch maps could be given to describe the flow regimes as shown in Fig.8. As the liquid flow rate increasing the flow regime in this cavitator could be described as follows:
(1) Cavitation vapour flow. This flow regime appears under a low flow rate. Several cavitation vapours were formed in the shear layer in the transition region between the annular aperture and the throat, as shown in Fig. 8 (a). Theses cavitation vapours flowed along the throat and quickly disappeared in the flow direction once the local pressure increased sufficiently.

(2) vapour cloud flow. As the liquid flow rate increasing, the jet velocity increased and produced a strong shear layer in the entrance of throat. Plenty of cavitation vapours coalesced into a vapour cloud structure in the entrance of throat and extended in the liquid flow direction, as shown in Fig. 8(b).

(3) Choking cavitation flow. As the liquid flow rate reached its maximum, the cavitation cloud was very large and became unstable. It broke into plenty of big cavitation vapours, flowing with liquid and finally developed into a homogeneous vapour-liquid as shown in Fig. 8(c). This homogeneous mixture accelerated in the flow direction until at a place where its velocity reached to its sonic velocity. Nilpueng and Wongwises (2011) defined this location as a choking section, behind which, vapourliquid homogeneous mixture would gradually transform to a single-liquid flow. Zhang et al. (2013) thought this section was important for dividing the flow into two isolate flows: the upstream flow which was a suitable for cavitation vapour grow up, the downward flow, which was suitable for vapour collapse.

\subsection{Degrading pollutants in liquid}

To investigate the capacity of degrading pollutants in wastewater, MB solution was treated in this experiment. Figure 9 showed the curves of MB concentration versus treating time at an inlet pressure 1.1 $\mathrm{MPa}$ and ambient pressure 0.66 MPa. It can be seen that the MB concentration continuously deceased with treatment time. Many researchers declaimed that $\mathrm{MB}$ concentration decreased exponentially with treatment time, and could be expressed as (Tao et al. 2017, Patil et al. 2014):

$$
C=C_{0} e^{-k t}
$$

where, $\mathrm{C}$ and $\mathrm{C}_{0}$ were $\mathrm{MB}$ concentrations at time $\mathrm{t}$ and the initial sate, respectively, $\mathrm{k}$ the degradation rate constant $\left(\mathrm{min}^{-1}\right)$. By curve-fitting, the degradation rate constant was about $0.0043 \mathrm{~min}^{-1}$.

The degradation rate of $\mathrm{MB}$ could be written as (Tao et al. 2017, Patil et al. 2014):

$D e=\frac{C_{0}-C}{C_{0}} \times 100 \%$

where, $D e$ represented degradation rate.

Figure 10 described the curves of $\mathrm{MB}$ degradation rate versus treatment time at inlet pressure $1.1 \mathrm{MPa}$ and an initial MB concentration $8 \mathrm{mg} / \mathrm{l}$. It was found that the degradation rate increased with treatment time. For different ambient pressures, this cavitation device showed some different degradation rates. The MB degradation rate in 60 minutes at different 


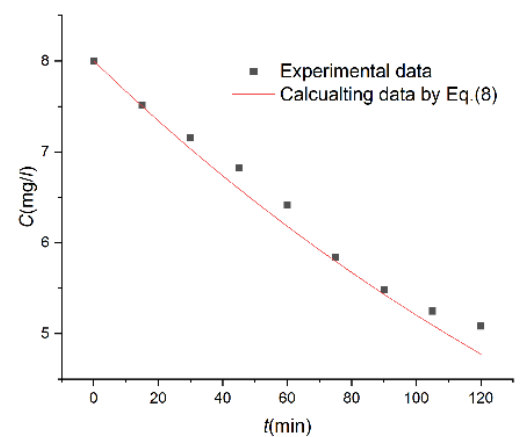

Fig. 9. MB concentration with treatment time.

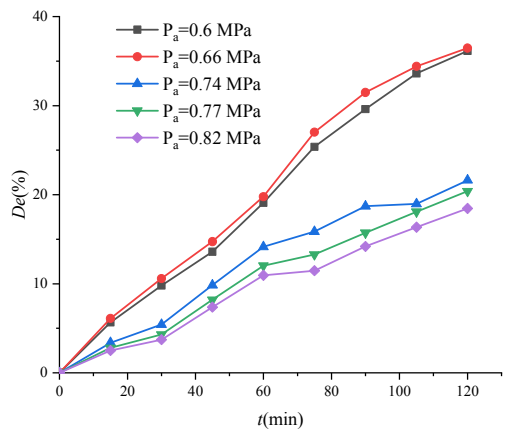

Fig. 10. MB degradation rate with treatment time under different ambient pressures.

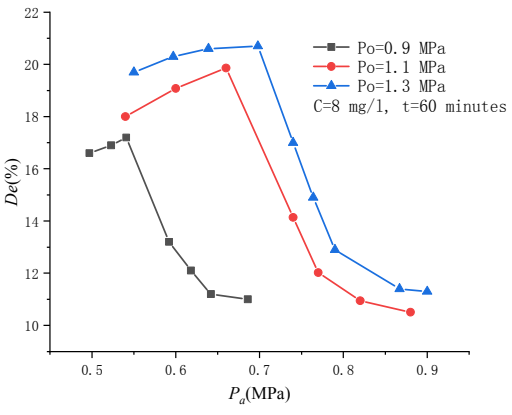

Fig. 11. MB degradation rate versus ambient pressure.

ambient pressures was shown in Fig. 11. For pump pressure $0.9,1.1,1.3 \mathrm{MPa}$, their curves of $\mathrm{MB}$ degradation rate could be divided into two different flow regions as depicted by the line. Take pump pressure $1.1 \mathrm{MPa}$ as an example. In the first region $(0.5 \mathrm{MPa}<\mathrm{Pa}<0.66 \mathrm{MPa}), \mathrm{MB}$ concentration increased with the increased ambient pressure. In the second region $(0.66 \mathrm{MPa}<\mathrm{Pa}<0.9 \mathrm{MPa}), \mathrm{MB}$ concentration decreased with the increased ambient pressure. Comparing these two regions, the degradation rates in the first region were much larger than those in the second one, which means the choking cavitation flow has a stronger decontamination effect than that of normal cavitation. For choking flow cavitation in its first region, a large ambient pressure was benefit for pollutant degradation, because vapour can more effectively collapse in the collapse cavity. But for the normal cavitation in the second region, a large ambient pressure would weaken the degradation effect, because this ambient pressure suppressed the formation and growth up of cavitation vapours. Thus, it could be found that an optimal working condition was the critical choking flow because cavitation flow was fully developed in the upstream flow and collapsed thoroughly in the downstream flow. Comparing the degradation rates under different pump pressures in Fig. 11, it could also be found that increasing the pump pressure could enhance the degradation rate, because the pump consumed more energy at a larger pump pressure.

\subsection{Effect of geometry parameters on degradation rate}

The effect of throat diameter on degradation rate in 60 minutes was shown in Fig. 12. With the increase of throat diameter, the degradation rate slowly increased and then decreased sharply. In fact, an increase of throat diameter would result in a decrease in jet velocity and a decrease in frictional loss along this throat, simultaneously. For throat diameter in 0 $10 \mathrm{~mm}$, the degradation rate increased because the ambient pressure became larger. For throat diameter in $10-14 \mathrm{~mm}$, the degradation rate decreased sharply because the number of cavitation vapours decreased under a slow jet velocity.

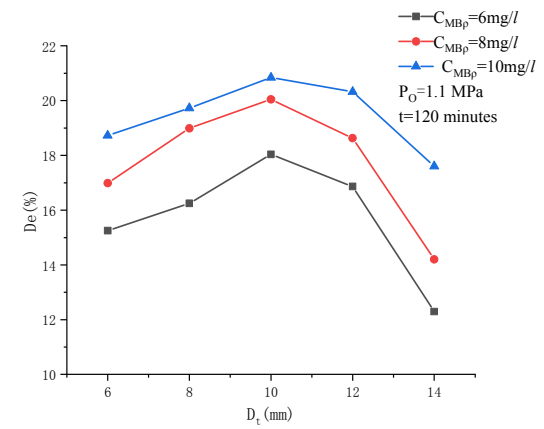

Fig. 12. Degradation rate versus throat diameter.

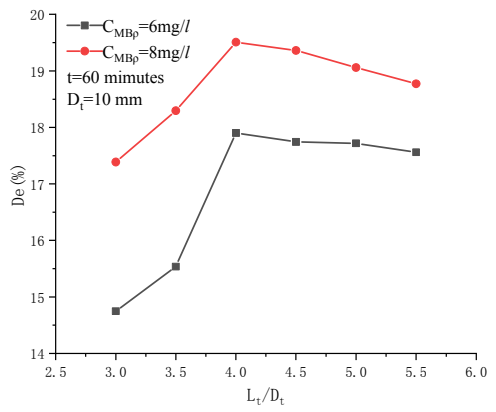

Fig. 13. Degradation rate versus throat length. 
The throat length also influenced the degradation rate, as shown in Fig. 13. Usually, there was a development section in the throat for vapour generation and growth up before forming a choking flow. It could be deduced in Fig. 13 that the cavitation flow was not fully developed in a short throat length below to $4 \mathrm{D}_{\mathrm{t}}$. Thus, the degradation ratio increased with the increase of throat length in a developing cavitation flow as shown in Fig. 13. When the throat length exceeded $4 \mathrm{D}_{\mathrm{t}}$, the cavitation flow has already been fully developed. Under this condition, a further increase of throat length would affect the ambient pressure in the downstream. Thus, the degradation ratio slightly decreased with the throat length when throat length exceeded $4 \mathrm{Dt}_{\mathrm{t}}$ as shown in Fig. 13.

The annular conical slot angle directly affected the formation of shear layer in the throat. Figure 14 showed the degradation ratio under different slot angles. It could be found that the degradation ratio increased with the increase of the slot angle at a small angle range $\left(\alpha<16^{\circ}\right)$. This was because the cavitation cloud became large in its shear layer. For a large slot angle $\left(\alpha>16^{\circ}\right)$, the degradation ratio decreased with an increase of slot angle, because a collision effect between the liquid jet from annular conical slot with the throat wall became stronger when increasing the slot angle. Thus, an appropriate slot angle of $16^{\circ}-18^{0}$ could be chosen for a better performance in pollutant degradation.

Form Fig. 12-15, it could be found that optimal geometry parameters for degradation rate were, throat diameter $10 \mathrm{~mm}$, throat length $4 \mathrm{D}_{\mathrm{t}}$, annular conical slot angle $16^{\circ}$.

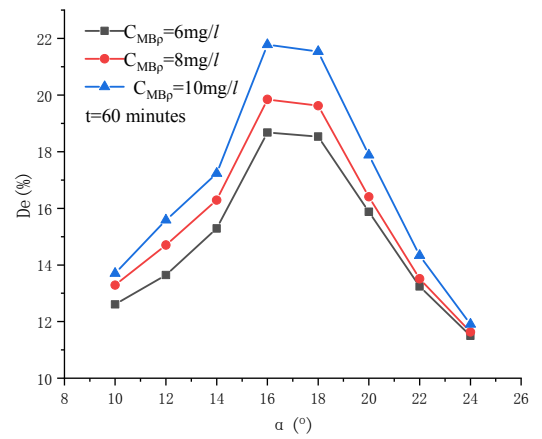

Fig. 14. Degradation rate versus slot angle.

\section{CONCLUSION}

A choking cavitation method was proposed for degrading pollutants in liquid. And a special cavitator, with a structure of an annular conical aperture, throat and a collapse cavity, was designed for forming a choking flow in the throat. A highspeed camera was employed to visually study the flow regime in this cavitator and a Mythylene blue (MB) degradation experiment was conducted for testing the pollutant degrading effect. The main results were listed as follows:
(1) Choking cavitation flow could be formed in this cavitator by controlling the pump pressure and its liquid flow rate. When keep the pump pressure and liquid flow rate in a rule of Eq. (4), a choking cavitation flow occurs and is not affected by the ambient pressure in the collapse cavity.

(2) Three flow regimes could be found when increasing the flow rate at a constant pump pressure in this cavitator: cavitation vapour flow, vapour cloud flow, choking cavitation flow. Choking cavitation flow is a homogeneous mixture flow with plenty of cavitation vapours evenly distributed in liquid. And these cavitation vapours would collapse when flowing through a choking section, and finally resulted in a strong degradation effect for pollutant.

(3) Choking cavitation has a much stronger degradation effect than the normal cavitation flow. The strongest cavitation appears in the critical choking flow, because the mixture in this condition reaches its maximal void fraction in the upstream flow and the vapours collapse thoroughly in the downstream flow.

(4) The geometry parameters of cavitator were investigated. The optimal geometry parameters for degradation rate are as follows, throat diameter 10 $\mathrm{mm}$, throat length $4 \mathrm{D}_{\mathrm{t}}$, annular conical slot angle $16^{0}$.

\section{ACKNOWLEDGEMENTS}

This research is financially by the Natural Science Foundation of Hunan Province, China (Grant No. 2020JJ5184) and by $\mathrm{PhD}$ early development program of Hunan University of Science and Technology (E52055)

\section{REFERENCES}

Akmandor, I. S. and T. Nagashima (2015). Predictions for cryogenic homogeneous twophase flows in a choked laval nozzle. Journal of Thermophysics and Heat Transfer 13, 355-363.

Badmus, K. O., J. O. Tijani, E. Massima and L. Petrik (2018). Treatment of persistent organic pollutants in wastewater using hydrodynamic cavitation in synergy with advanced oxidation process. Environmental Science and Pollution Research 25, 7299-7314.

Didenko, Y. T., W. B. Mcnamara and K. S. Suslick (1999). Hot spot conditions during cavitation in water. Journal of the American Chemical Society 121, 5817-5818.

Griebe, R. W., R. J. Schoenhals and E. Winter (1970). Choking and shock phenomena in a single component two-phase flow including vibrational effects. Wärme - und Stoffübertragung 3, 7-18.

Langone, M., R. Ferrentino and G. Trombino (2015). Application of a novel hydrodynamic cavitation system in wastewater treatment plants. $U P B$ Scientific Bulletin, Series D: Mechanical 
Z. Wang et al. / JAFM, Vol. 15, No. 1, pp. 245-253, 2022

Engineering 77, 225-234

Li, D., Y. Kang and X. L. Ding (2017). Experimental study on the effects of feeding pipe diameter on the cavitation erosion performance of selfresonating cavitating waterjet. Experimental Thermal and Fluid Science 82, 314-325.

Li, D., Y. Kang and X. L. Ding (2016). Effects of area discontinuity at nozzle inlet on the characteristics of high-speed self-excited oscillation pulsed waterjets. Experimental Thermal and Fluid Science 79, 254-265.

Li, D., Y. Kang and X. L. Ding (2016). Effects of nozzle inner surface roughness on the cavitation erosion characteristics of high-speed submerged jets. Experimental Thermal and Fluid Science 74, 444-452.

Liu, W. C., Y. Kang and M. X. Zhang (2017). Selfsustained oscillation and cavitation characteristics of a jet in a Helmholtz resonator. International Journal of Heat and Fluid Flow $68,158-172$.

Lohani, U. C., K. Muthukumarappan and G. H. Meleharayil (2016). Application of hydrodynamic cavitation to improve antioxidant activity in sorghum flour and apple pomace. Food and Bioproducts Processing 100, 335-343.

Mancuso, G., M. Langone and G. Andreottola (2016). A swirling jet-induced cavitation to increase activated sludge solubilisation and aerobic sludge biodegradability. Ultrasonics Sonochemistry 35,489-501.

Nilpueng, K. and S. Wongwises (2011). Choked flow mechanism of HFC-134a flowing through short-tube orifices. Experimental Thermal and Fluid Science 35, 347-354.

Pawar, S. K., A. V. Mahulkar and A. B. Pandi (2017). Sonochemical effect induced by hydrodynamic cavitation: Comparison of venturi/orifice flow geometries. AICHE Journal 63, 4705-4716.

Patil, P. N., S. D. Bote and P. R. Gogate (2014). Degradation of imidacloprid using combined advanced oxidation processes based on hydrodynamic cavitation. Ultrasonics
Sonochemistry 21, 1770-1777.

Rajoriya, S., S. Bargole and V. K. Saharan (2017). Degradation of a cationic dye (Rhodamine 6G) using hydrodynamic cavitation coupled with other oxidative agents: Reaction mechanism and pathway. Ultrasonics Sonochemistry 34, 183-194.

Rouse, H. and A. H., Abul-fetouh (1950). Characteristics of irrotational flow through axially symmetric orifices. Journal of Applied Mechanics- Transactions of the ASME 17, 421423.

Sarc, A., T. Stepisnikperdih and M. Petkovsek (2017). The issue of cavitation number value in studies of water treatment by hydrodynamic cavitation. Ultrasonics Sonochemistry 34, 5159.

Sivakumar, M. and A. B. Pandit (2002). Wastewater treatment: A novel energy efficient hydrodynamic cavitational technique. Ultrasonics Sonochemistry 9, 123-131.

Tao, Y. Q., J. Cai and X. Huai (2017). A novel device for hazardous substances degradation based on double-cavitating-jets impingement: Parameters optimization and efficiency assessment. Journal of Hazardous Materials 335, 188-196.

Trapp, J. A. and V. H. Ransom (1982). A chokedflow calculation criterion for nonhomogeneous, nonequilibrium, two-phase flows. International Journal of Multiphase Flow 8, 669-681.

Vichare, N. P., P. R. Gogate and A. B. Pandit (2000). Optimization of Hydrodynamic Cavitation Using a Model Reaction. Chemical Engineering and Technology 23, 683-690.

Wang, X., J. Wang and P. Guo (2008). Chemical effect of swirling jet-induced cavitation: degradation of rhodamine B in aqueous solution. Ultrasonics Sonochemistry 15,357-363.

Zhang, F. H., H. F. Liu and J. C. Xu (2013). Experimental investigation on noise of cavitation nozzle and its chaotic behaviour. Chinese Journal of Mechanical Engineering 26, 758-762. 